\title{
Process of home health services provided to patients with gastrointestinal cancers in Turkey
}

\section{Türkiyede gastrointestinal sistem kanseri olan hastalarda evde sağlık hizmetlerinin gelişimi}

\author{
Fatih Göksel ${ }^{1}$ L Lütfi Doğan² \\ ${ }^{1}$ Sb Dr. Abdurrahman Yurtarslan Ankara Onkoloji Eğitim ve Araştırma Hastanesi, Radyasyon Onkolojisi \\ Kliniği, Ankara \\ ${ }^{2} \mathrm{Sb}$ Dr. Abdurrahman Yurtarslan Ankara Onkoloji Eğitim ve Araştırma Hastanesi, Genel Cerrahi Kliniği, \\ Ankara
}

\section{ÖZET}

GİRIŞ ve AMAÇ: Kanser tedavisindeki gelişmeler ve yenilikler sayesinde hemen hemen tüm kanser türlerinde sağkalımda artışlar dikkat çekmektedir. Metastatik hastalarda dahi uzun sağkalım süreleri olanaklı hale gelmiştir. Sonuç olarak karşımıza uzun süredir değişik evrelerde kanser tanısı ile yaşamını sürdürmüş ancak sürekli sağlık hizmetine ihtiyaç duyan bir hasta grubu çıkmaktadır. Bu çalışma ülkemizde gastrointestinal sistem malignitesi tanılı hastalara sunulan Evde Sağlık Hizmetleri (ESH)'nin ülkemizdeki faaliyet sürecinin değerlendirilmesi amacı ile planlanmıştır.

YÖNTEM ve GEREÇLER: 2011-2017 yılları arasında ösafagus, mide, ince barsak, kolon, rektum, karaciğer, pankreas ve safra yolu malign neoplazmı tanısı almış hastalara sunulan ESH kapsamında ulaşılan hasta, yapılan vizit sayıları ve hizmet sunan ekip sayıları değerlendirildi.

BULGULAR: Nörolojik ve psikiyatrik hastalıklar, kardiyovasküler hastalıklar ve ortopedik hastalıklardan sonra kanser hastaları ESH'ni en sık alan 4. grup hastalığı oluşturmaktadır. Türkiyede 2011 yılında, toplam 593 hizmet ekibi ile başlayan ESH'inde, 2017 yılına gelindiğinde ekip sayısının 662'ye yükseldiği görülmektedir. 2011 yılında toplam yapılan vizit sayısı 344.014 iken 2017 yılında bu rakam 10.917.965 olarak gerçekleşmiştir. 2011 yllında 7278 vizit, kanserli hastalar için yapılmış iken 2017 yllında bu rakam 74.261 dir. Toplam GIS maligniteli hasta vizit sayıs 7 yıl içerisinde 89.389 olarak gerçekleşmiştir.

TARTIŞMA ve SONUÇ: GIS malignitesi olan hastalara verilen evde bakım vizitlerinin sayılarının, malignitelerin insidansı ile doğru orantılı olduğu görülmektedir. Buna göre kolon, mide ve pankreas kanserli hastalar en çok vizit yapılan hastalardır. ESH kapsamında vizit sunulan hasta sayısının yıllar içerisinde kademeli bir artış gösterdiği görülmektedir. ESH'nin bakanlık politikası haline getirilmesi, ekip sayılarının arttırılarak hizmete ulaşmanın kolaylaşması ve gerek sağlık profesyonelleri, gerekse hasta ve yakınları tarafından farkındalığın artmış olması bu artışın temel sebepleri olarak karşımıza çıkmaktadır.

Anahtar Kelimeler: Kanser, evde sağlık, gastrointestinal kanser.

\begin{abstract}
INTRODUCTION: Improvements and innovation in cancer treatment led to prolongation of survival in almost every cancer type. Longer survival of even patients with metastasis has become possible. As a result, there is an increasing number of patients who have survived with the diagnosis of cancer in different stages in need of continuous health support. This is study is designed to evaluate the process of Home Health Services (HHS) provided to patients with gastrointestinal cancers in our country.

METHODS: Patients with a diagnosis of esophageal, gastric, small intestine, colon, rectum, hepatic, pancreatic or bile duct malignancy between 2011 and 2017 were reviewed for HHS coverage, home visit frequency and HHS-providing medical staff.

RESULTS: Cancer patients are the fourth, after patients with neuropsychiatric disorders, cardiovascular diseases, and orthopedic disorders, that receive HHS support. HHS has started in 2011 with 593 teams in Turkey. The number of teams providing HHS increased to 662 by the end of the year 2017. Total home-visits have dramatically risen from 344,014 to $10,917,965$ during a 7-year period. Home-visits to cancer patients have also increased from 7,278 in 2011 to 74,261 in 2017. A total of 89,389 home-visits were made to patients with gastrointestinal cancers.
\end{abstract}


DISCUSSION AND CONCLUSION: The number of home-visits to patients with gastrointestinal cancers had increased as the incidence of these diseases increased. Data show that colon, gastric and pancreatic cancer patients were among the most visited patients. The number of home-visits by HHS departments showed a steady increase in years. The main reasons for this increase are that the HHS has become a ministerial policy, the number of teams has increased and the access to service has been facilitated and the health professionals and the patients and their relatives had increased awareness.

Keywords: Cancer, home care, gastrointestinal cancer.

\section{GíRiș}

Tüm dünyada ortalama insan ömrünün artmasına paralel olarak nüfusun hızla yaşlandığı görülmektedir. $\mathrm{Bu}$ durum beraberinde tüm kanser vakalarında artışı da beraberinde getirmektedir. Kanser tedavisindeki gelişmeler ve yenilikler sayesinde hemen hemen tüm kanser türlerinde sağkalımda artışlar dikkat çekmektedir. Metastatik hastalarda dahi uzun sağkalım süreleri olanaklı hale gelmiştir. Sonuç olarak karşımıza uzun süredir değişik evrelerde kanser tanısı ile yaşamını sürdürmüş ancak sürekli sağllk hizmetine ihtiyaç duyan bir hasta grubu çıkmaktadır. Özellikle gastrointestinal sistem (GIS)maligniteli hastaların uzunca bir dönem palyatif tedavi gereksinimleri devam eder. $\mathrm{Bu}$ durum hasta ve yakınları açısından oldukça meşakkatli ve yorucu bir süreç olduğu gibi sağlık çalışanları ve sağlık sistemi açısından da büyük bir iş yüküdür. Günümüzde artan hasta sayısı ve çeşitliliği sebebi ile hekimler hasta yataklarını efektif kullanmak ve yatak devir hızlarını belli seviyelerde tutmak zorundadırlar. Sağlık sistemleri ise her geçen yıl daha fazla sayıda ve çeşitte sağlık hizmetini finanse etmek durumunda kalmaktadir. Ülkemizde palyatif bakım servisleri ve yatak sayılarında artışlar olsa da halen bu konuda tedaviye ve yardıma duyulan ihtiyaçların önemli bir kısmı karşılanamamaktadır.

Ülkemizde 2011 yılından beri Sağlık

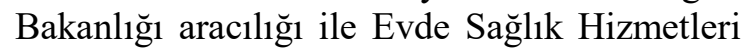
(ESH) adı altında, ihtiyaç duyan hastalara ev ortaminda sunulabilecek muayene ve manuplatif tıp hizmetleri sunulmaktadır.2015 yılında. Sağlık Bakanlığı tarafindan yayımlanan yönetmelik ile evde sağlık hizmetlerinin yasal düzenlemesi yeniden yapılmıştır. İlk düzenlemede hastanelere bağlı birimlere ek olarak 81 ilin il sağlık müdürlükleri bünyesinde birimler kurulmuş, 2017 yılından itibaren ağırlıklı olarak hastane temelli yapılanma kalmıştır. Şu an için evde sağlık hizmeti sadece devlet kurumları tarafından verilmekte ve sağlık bakanlığ kaynaklarından katk1 payı olmadan karşılanmaktadır.

Ülkemizde evde sağlık hizmetleri hastanın telefon ile başvurusu üzerine verilmektedir. Bu şekilde başvuru kaydı alınan hastanın bulunduğu bölgeden sorumlu evde sağlik hizmet birimine hasta bilgileri gönderilmekte ve birimin belirli bir sürede ilk ziyareti gerçekleştirmesi gerekmektedir. İlk ziyarette ekipte bulunan hekim hastanın ne kadar süreyle ne siklıkta ve nasil bir evde sağlık hizmetine ihtiyaç duyduğunu belirlemekte ve listesine almaktadır. Hizmet almasına gerek olmayanları da dosyasında belirterek programdan çıkarmaktadır.

Ülkeler arasındaki sağlık sistemlerinin ve sosyokültürel yapıların farklılığı nedeniyle evde sağllk hizmetinin sunum şekli ülkeden ülkeye farkl11ık gösterir (1). $\mathrm{Bu}$ çalışma ülkemizde gastrointestinal sistem malignitesi tanılı hastalara sunulan ESH'nin ülkemizdeki faaliyet sürecinin değerlendirilmesi amacı ile planlanmıştır.

\section{MATERYAL ve METOD}

Çalışma için Sağlık Bakanlığına müracaat edilerek 2011 y1lından itibaren ülkemizde yürütülen ESH faaliyetleri ile ilgili çalışma raporları istenmiş ve çalışma ile ilgili gerekli izinler alınmıştır. 2011-2017 yılları arasında ösafagus, mide, ince barsak, kolon, rektum, karaciğer, pankreas ve safra yolu malign neoplazmı tanısı almış hastalara sunulan ESH kapsamında ulaşılan hasta, yapılan vizit sayıları ve hizmet sunan ekip sayıları değerlendirildi.

2011-2017 y1lları arasını kapsayan toplam 7 ylllik veri Microsoft Excel, 2016 version (Microsoft Co., Menlo Park, California) yazılımı kullanılarak analiz edilmiştir. 


\section{SONUÇLAR}

Nörolojik ve psikiyatrik hastalıklar, kardiyovasküler hastalıklar ve ortopedik hastalıklardan sonra kanser hastaları ESH'ni en s1k alan 4. Grup hastalığ oluşturmaktadır. Türkiye'de 2011 yilında, toplam 593 hizmet ekibi ile başlayan ESH'inde 2017 yılına gelindiğinde ekip sayısının 662'ye yükseldiği görülmektedir. 2011 yılında toplam yapılan vizit say1s1 344.014 iken 2017 y1linda bu rakam 10.917.965 olarak gerçekleşmiștir. 2011 y1lında 7278 vizit kanserli hastalar için yapılmış iken 2017 yılında bu rakam 74.261 dir. Ösafagus, mide, karaciğer, kolon, pankreas, ince barsak ve safra yolu kanserli hastalara yapılan vizit sayısının yıllara göre dağılımı tablo-1 de gösterilmiştir. 2011 yılı baz alınarak GIS kanseri olan hastalara yapılan yıllık vizit artış oranları ise tablo-2 de gösterilmiştir. 2011 y1lından başlayarak 7 yıl içerisinde 32.232 kolon, 26.780 mide, 9.749 karaciğer, 10.818 pankreas, 4.409 ösafagus, 3.286 safra yolu ve 2.115 ince barsak kanseri tanılı hasta viziti gerçekleştirilmiştir. Toplam GIS maligniteli hasta vizit sayıs 7 y1l içerisinde 89.389 olarak gerçekleşmiştir. En s1k vizit verilen kolon, mide ve pankreas kanseri tanılı hastalardaki ve toplam GIS kanserli hastalardaki vizit sayılarını gösteren grafikler şekil 1-4 de gösterilmiştir.

Tablo-1. Türkiyede yıllara göre evde bakım vizit sayıları

\begin{tabular}{|c|c|c|c|c|c|c|c|c|c|c|}
\hline & $\begin{array}{l}\text { Birim } \\
\text { Sayıs } \\
1\end{array}$ & \begin{tabular}{|l} 
Topla \\
m \\
Vizit \\
Sayis \\
1
\end{tabular} & \begin{tabular}{|l} 
Kans \\
erli \\
hasta \\
vizit \\
sayis1
\end{tabular} & $\mid \begin{array}{l}\text { Ösafa } \\
\text { gus } \\
\text { kanse } \\
\text { ri } \\
\text { vizit } \\
\text { sayıs1 }\end{array}$ & \begin{tabular}{|l} 
Mide \\
kanse \\
ri \\
vizit \\
sayisi
\end{tabular} & \begin{tabular}{|l|} 
İnce \\
barsa \\
k \\
kanse \\
ri \\
vizit \\
sayıs1 \\
\end{tabular} & $\mid$\begin{tabular}{|} 
Karac \\
iğer \\
kanse \\
ri \\
vizit \\
sayısı
\end{tabular} & \begin{tabular}{|l} 
Kolo \\
n \\
Kans \\
eriviz \\
it \\
sayisı
\end{tabular} & $\begin{array}{l}\text { Pankr } \\
\text { eas } \\
\text { Kans } \\
\text { eriviz } \\
\text { it } \\
\text { say1s1 }\end{array}$ & $\begin{array}{l}\text { Safra } \\
\text { yolu } \\
\text { kanse } \\
\text { ri } \\
\text { vizit } \\
\text { sayis1 }\end{array}$ \\
\hline 2011 & 593 & \begin{tabular}{|l|}
344.0 \\
14
\end{tabular} & 7.278 & 55 & 638 & 31 & 159 & 705 & 171 & 101 \\
\hline 2012 & 628 & \begin{tabular}{|l|}
2.300 \\
.497 \\
\end{tabular} & $\begin{array}{l}35.16 \\
1\end{array}$ & 329 & 2.760 & 193 & 1.064 & 3.053 & 1033 & 379 \\
\hline 2013 & 685 & $\begin{array}{l}3.839 \\
.634 \\
\end{array}$ & $\begin{array}{l}46.50 \\
7\end{array}$ & 516 & 3.548 & 314 & 1.398 & 4.133 & 1391 & 409 \\
\hline 2014 & 711 & \begin{tabular}{|l|}
5.463 \\
.473 \\
\end{tabular} & \begin{tabular}{|l}
33.70 \\
1 \\
\end{tabular} & 777 & 4.207 & 460 & 1.598 & 4.885 & 1516 & 543 \\
\hline 2015 & 721 & $\begin{array}{l}7.199 \\
.535 \\
\end{array}$ & $\begin{array}{l}61.47 \\
7 \\
\end{array}$ & 954 & 4.652 & 373 & 1.539 & 5.680 & 1864 & 487 \\
\hline 2016 & 716 & \begin{tabular}{|l|}
9.688 \\
.104 \\
\end{tabular} & $\begin{array}{l}74.99 \\
7 \\
\end{array}$ & 897 & 5.713 & 399 & 2.114 & 6.774 & 2471 & 792 \\
\hline 2017 & 662 & $\begin{array}{l}10.91 \\
7.965 \\
\end{array}$ & $\begin{array}{l}74.26 \\
1\end{array}$ & 881 & 5.262 & 345 & 1.877 & 7.002 & 2372 & 575 \\
\hline
\end{tabular}

Tablo-2 Y1llik Kanserli Hastalara yapılan Vizit Artış Hızları

\begin{tabular}{|c|c|c|c|c|c|c|c|c|}
\hline & $\begin{array}{l}\text { Kanse } \\
\text { rli } \\
\text { hasta } \\
\text { vizit } \\
\text { artıș }\end{array}$ & $\begin{array}{l}\text { Ösafagu } \\
\text { s } \\
\text { kanseri } \\
\text { vizit } \\
\text { artıșı }\end{array}$ & $\begin{array}{l}\text { Mide } \\
\text { kanse } \\
\text { ri } \\
\text { vizit } \\
\text { sayıs1 }\end{array}$ & $\begin{array}{l}\text { İnce } \\
\text { barsak } \\
\text { kanseri } \\
\text { vizit } \\
\text { sayısı }\end{array}$ & $\begin{array}{l}\text { Karaciğ } \\
\text { er } \\
\text { kanseri } \\
\text { vizit } \\
\text { sayısı }\end{array}$ & \begin{tabular}{|l} 
Kolon \\
Kanseri \\
vizit \\
say1s1
\end{tabular} & $\begin{array}{l}\text { Pankrea } \\
\text { s } \\
\text { Kanseri } \\
\text { vizit } \\
\text { sayis1 }\end{array}$ & \begin{tabular}{|l} 
Safra \\
yolu \\
kanseri \\
vizit \\
say1s1
\end{tabular} \\
\hline 2011 & - & - & - & - & - & - & 7 & - \\
\hline 2012 & $\% 569$ & $\% 498$ & $333 \%$ & $523 \%$ & $569 \%$ & $333 \%$ & $504 \%$ & $275 \%$ \\
\hline 2013 & $\% 67$ & $\% 57$ & $29 \%$ & $63 \%$ & $31 \%$ & $35 \%$ & $35 \%$ & $8 \%$ \\
\hline 2014 & $\% 42$ & $\% 51$ & $19 \%$ & $46 \%$ & $14 \%$ & $18 \%$ & $9 \%$ & $33 \%$ \\
\hline 2015 & $\% 32$ & $\% 23$ & $11 \%$ & $19 \%$ & $4 \%$ & $16 \%$ & $23 \%$ & $10 \%$ \\
\hline 2016 & $\% 35$ & $\% 6$ & $23 \%$ & $7 \%$ & $37 \%$ & $19 \%$ & $33 \%$ & $63 \%$ \\
\hline 2017 & $\% 13$ & $\% 2$ & $8 \%$ & $14 \%$ & $11 \%$ & $3 \%$ & $4 \%$ & $27 \%$ \\
\hline
\end{tabular}

Şekil-1. Toplam kanserli hasta vizit sayısı

$$
\begin{gathered}
\text { Toplam Kanserli Hasta Vizit } \\
\text { Sayis1 }
\end{gathered}
$$

100000

50000

0

2011201220132014201520162017

Şekil 2. Mide kanseri vizit sayısı

Mide Kanseri Vizit Say1s1

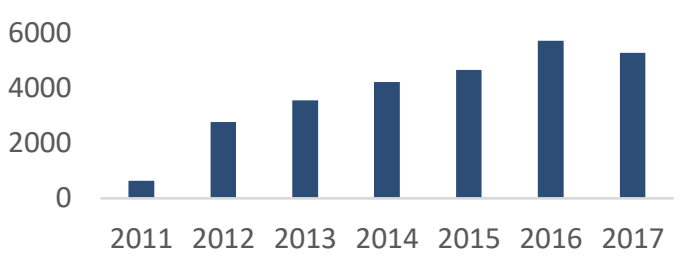

Şekil 3. Kolon kanseri vizit sayısı Kolon Kanseri Vizit Say1s1

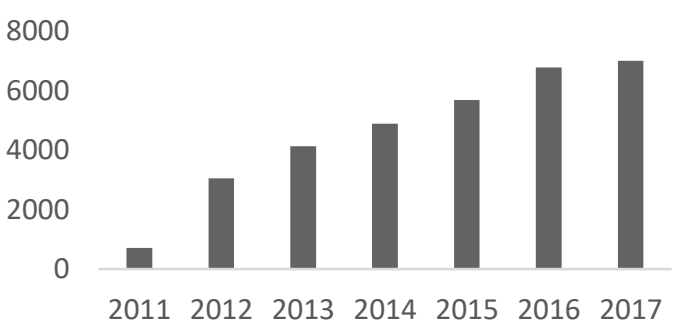


Şekil 4. Pankreas kanseri vizit sayısı

Pankreas Kanseri Vizit Sayıs1

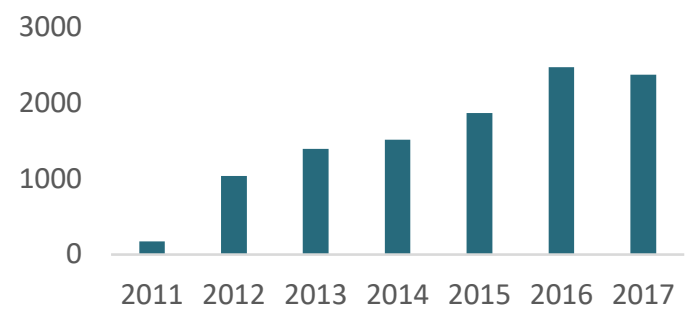

\section{TARTIŞMA}

Tıbbi açıdan definitif tedavi şansı olmayan hastaların palyatif tedavi ve destek hizmet almaları en temel haklarından biridir. (2). Günümüzde bütün dünya da palyatif bakım ihtiyacı olan hastaların önemli bir kısmı bu tedavilerini sağlik kuruluşlarında almak zorundadırlar. Palyatif bakım hizmeti sunulan servis ve yatak sayısı kısıtlı olduğundan bu tedaviler ya kliniklerde geçici olarak yatırılarak ya da polikliniklerde ayaktan hizmet tarzında verilmektedir. Bu durum hasta ve yakınlarında tatminsizlik, yorgunluk, bezginlik ve işgücü kaybına yol açarken sağlık hizmeti finansmanında da ciddi giderlere neden olmaktadır. 2000 li yıllarda bu tip sorunlarla yüzleşen sağlık camiası bu gibi hastaların sağlık kuruluşlarında bakılmasının şart olmadığını ve evlerinde de etkin bir hizmetin sunulabileceğini ortaya atmıştır. Başta Amerika BD ve batı Avrupa ülkelerinde sunulmaya başlanan ESH özellikle palyatif bakım ihtiyacı duyan hastalara sağlık hizmeti vermenin en rasyonel yollarlından biri haline gelmiştir. ESH tüm dünyada hükümetlerin en çok geliştirmeye çalıştıkları sağlık politikalarından biri haline gelmiştir. Dünyada ciddi sağlı sorunları olan insanların ölümlerinin önemli bir bölümünün evlerinde gerçekleştiği görülmektedir (3). Brunley ve ark Amerikan sağlık sistemi içerisinde ESH nin maliyet etkin olduğunu ortaya koymuştur (4).

Hasta ve yakını kendi özel çevresini en rahat ve güvenli alan olarak tanımlar. Palyatif bakım ihtiyacı duyan kanser hastalarının yarısından fazlasının bu hizmetleri hastane yerine evde almayı tercih ettikleri bilinmektedir (5). Hastalar aynı hizmeti evde aldıkları zaman bu hizmeti çok daha etkin ve konforlu olarak tanımlamaktadırlar (6).
Hastane de yatarak uzun süre tedavi görmek durumunda olan palyatif bakım hastaları için en önemli sorunlar, hastane ortamının enfeksiyona açık olması, psikolojik açıdan hasta yakınları için yıpratıcı olmasıdır. Ayrıca hastanede yatışın bu hastalar için yapılan gereksiz tetkikleri arttırdığı bilinmektedir (7).

Düzenli beslenememe, kilo kaybı, kronik ağrılar, ostomi ile ilgili bakım problemleri, geçirilmiş batın cerrahisine bağlı problemler GIS malignitesi bulunan hastalarda en sık karşılaşılan kronik sorunlardır. Palliative Care Outcome Scala (PCOS) ölçümleri ile yapılan çalışmalar sonucunda palyasyon ve semptom kontrolü konusunda ESH'nin, polikliniklerde verilen hizmetlere göre daha başarılı olduğu ortaya konulmuştur (8). PCOS sonuçlarına göre en fazla iyileşme sağlanan semptom kronik ağrıdır. Bunda hastaların doğal ev ortamında olmalarının psikolojik olumlu etkisi olabilir. Nefes darlığı, uyku düzensizliği, bulant,, kusma, diyare ve konstipasyon, iştahsızlık ESH ile başarılı ve tatminkar bir şekilde tedavi edilebilen kronik semptomlar arasındadır. ESH ve poliklinik hizmeti alan palyatif tedavi ihtiyacı duyan GIS malignitesi alan hastalara uygulanan Yaşam Kalite (QOL) anketlerinde gerek fiziksel gerekse psikolojik iyilik halinin ESH alan hastalarda yüksek olduğu ortaya konulmuştur. Hasta yakınlarına uygulanan ölçeklerde de benzer sonuçlarla karşılaşılmıştır. Özellikle ESH alınmaya başlanmasını takip eden ilk 30 günde, ESH alan hastaların memnuniyet derecesi, poliklinik hizmeti alan hastaların 3 katına çıkmaktadır (8). Jordoy ve ark ESH alan hastalarda en yüksek memnuniyet derecesinin yaşlı ve GIS malignitesi olan hastalar olduğunu bildirmiştir (9). Rabow ve ark nın çalışmasında ise düzenli ESH alan hastalarda Acil servis ve normal poliklinik başvuru sayılarının azaldığ 1 ayrıca bu hastalarda ilaç kullanımının düzene girdiği ya da azalttığı ortaya konulmuştur (10). Profesyonel bir hizmete ulaşabilme imkanı hatta bu hizmetin bizzat ev ortamında verilme şekli hasta ve yakınlarında ciddi güven duygusu oluşturur. Sağlık hizmeti yanında hasta ve yakınlarının önemli bir gereksinimi de fikir danışmak, bilgi almak ve sağlık profesyonellerinin görüşlerine başvurmaktır. ESH bu ihtiyaçlara kolaylıkla karşılık verebilir (8). ESH' nin ayn ekiple hastaya hizmet vermesi, karş1lıklı güven duygusunu ve ulaşılabilirliği geliştirir. Bir süre sonra ihtiyaç 
duyulan destek ve hizmet, telefon aracıllı̆ $\breve{1}_{1}$ ile bile sunulabilir hale gelir. Ekipler, hasta yakınlarına basit girişimsel işlemleri öğretip ciddi zaman tasarrufu sağlayabilirler. Hasta yakınlarının ESH ekiplerinden bir diğer faydalanma şekli de hastaya ait vicdani sorumlulukların paylaşılmasıdır. Hasta yakınları, hastalarının ciddi şikayetleri olmasa da sağlı kuruluşu ile irtibat halinde olunmamasının toplumsal eleştiri ve vicdani baskı oluşturduğunu ifade etmektedirler.

ESH'nin semptom kontrolü konusundaki başarısının ortaya konması ve hasta ve yakınları tarafindan memnuniyetle karşılanmasını takiben sunulan hizmetler arttırılmaya ve çeşitlendirilmeye başlamıştır (11). Uygulanan model, hizmet ve amaçlar çok farklı olduğu için ideal bir model ya da ekolden bahsetmek mümkün değildir. Ülkeler kendi demografik yapıları, sağlık ve sigorta sistemleri dahilinde kendi sistemlerini geliştirmelidirler. ESH artık ciddi bir klinik hizmet alanı ve sağlık ve sosyal hizmet politikası haline gelmiştir. Gelecekte çok daha fazla önem kazanacağı açıktır. Ekipler içerisinde palyasyon ve semptom kontrolü sağlayacak yetkin uzmanların bulunması gerekir. Hizmetlerin devamlılığ 1 ve 24 saat verilebilmesi hizmet kalitesini arttıracaktır. Ekipler üstlendikleri görevin önem ve sorumluluğunu iyi kavramalıdır. Çalışmamızda GIS malignitesi olan hastalara verilen evde bakım vizitlerinin sayılarının, malignitelerin insidans1 ile doğru orantılı olduğu görülmektedir. Buna göre kolon, mide ve pankreas kanserli hastalar en çok vizit yapılan hastalardır. ESH kapsamında vizit sunulan hasta sayısının yıllar içerisinde kademeli bir artış gösterdiği görülmektedir. ESH'nin bakanlık politikası haline getirilmesi, ekip sayılarının arttırılarak hizmete ulaşmanın kolaylaşması ve gerek sağlık profesyonelleri, gerekse hasta ve yakınları tarafindan farkındalığın artmış olması bu artışın temel sebepleri olarak karşımıza çıkmaktadır.

Kanser hastalarına verilen ESH'nin kalitesinin, ekonomik katkısının, semptom palyasyonu açısından etkinliğinin, kaynakların etkin kullanılıp kullanılmadığının ortaya konulması için ulusal çalışmalara ihtiyaç vardır. $\mathrm{Bu}$ çalışmalar hizmetin çok daha başarılı bir şekilde verilmesi için yol gösterici olacaktır.

\section{REFERANSLAR}

1. Steven L, Elizabeth $\mathrm{M}$, Bruce $\mathrm{L}$, Robert JR, Barbara AM, Rodney $\mathrm{H}$, et al. The future of home health care: a strategic framework for optimizing value. Home Health Care Manag Pract. 2016;28(4):262-278.

2. UN General Assembly, Universal Declaration of Human Rights,10 December 1948, 217 A (III), available http://www.refworld.org/docid/3ae6b3712c.html (accessed 13 Feb 2016).

3. World Health Organisation Executive Board. Resolution EB134.R7: strengthening of palliative care as a component of integrated treatment within the continuum of care. 2014. http://apps.who.int/gb/ebwha/pdf_files/EB134/B13 4_R7-en.pdf

4. Brumley R, Enguidanos S. Findings from a multisite inhome palliative care study. Journal of Palliative Care 2006;22(3):199.

5. European Association for Palliative Care (EAPC). White Paper on standards and norms for hospice and palliative care in Europe: recommendations from the European Association for Palliative Care. Eur J Palliat Care 2009;16:278-89.

6. Ventura Mde M.Effectiveness and costeffectiveness of home palliative care services for adults with advanced illness and their caregivers. Sao Paulo Med J. 2016;134(1):93-4. doi: 10.1590/1516-3180.20161341T2.

7. Connor SR, Bermedo MCS, eds. Global atlas of palliative care at the end of life. World Palliative Care Alliance \& World Health Organisation, 2014.

8. Gomes B, Calanzani N, Curiale V, McCrone P, Higginson IJ. Effectiveness and cost-effectiveness of home palliative care services for adults with advanced illness and their caregivers. Cochrane Database Syst Rev. 2013;6,6.CD007760. doi:10.1002/14651858.CD007760.pub2.

9. Fredheim OMS, Kaasa $S$, Fayers $P$, Saltnes $T$, Jordhøy M, Borchgrevink PC. Chronic nonmalignant pain patients report as poor healthrelated quality of life as palliative cancer patients. Acta Anaesthesiologica Scandinavica 2008;52(1):143-8

10. Rabow MW, Dibble SL, Pantilat SZ, McPhee SJ. The Comprehensive Care Team: a controlled trial of outpatient palliative medicine consultation. Archives of InternalMedicine 2004;164(1):83-91.

11. Centeno $C$, Lynch $T$, Donea $O$, et al. EAPC Atlas of Palliative Care in Europe 2013. Full Edition. Milan: EAPC Press; 2013. 